\title{
Correction to: Experimental Investigation of In-Homogeneity in Particle Distribution during the processing of Metal Matrix Composites
}

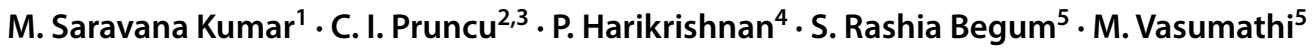

Published online: 7 February 2022

(c) Springer Nature B.V. 2022

\section{Correction to: Silicon}

\section{https://doi.org/10.1007/s12633-020-00886-4}

The authors found mistakes in their article noted above. Therefore, authors have performed a comprehensive characterization and presented in this corrigendum. It notes that these errors could not affect the results and conclusion

of this study. The authors would like to apologize for any inconvenience caused.

The authors regret that in the above article, Figs. 6 contained errors and were corrected as follows:
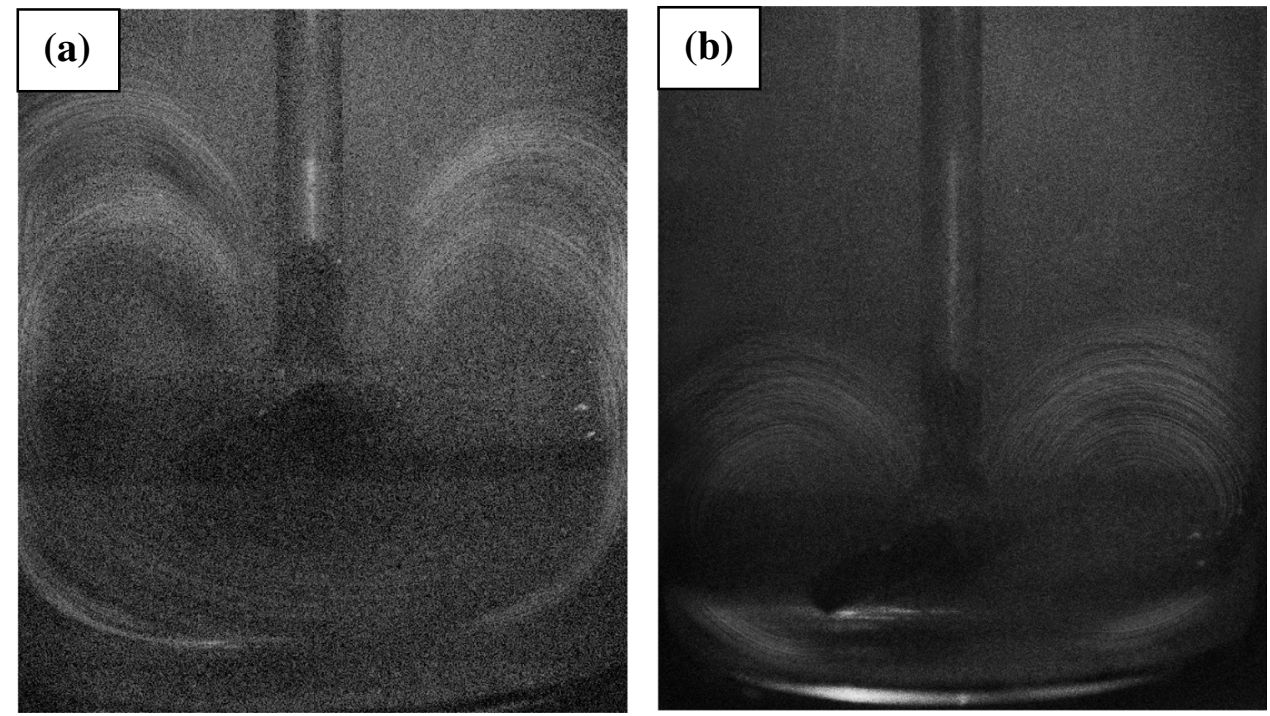

The original article can be found online at https://doi.org/10.1007/ s12633-020-00886-4.

M. Saravana Kumar saravana312@gmail.com

1 Department of Mechanical Engineering, Mount Zion College of Engineering and Technology, , Tamilnadu, Pudukottai, India

2 Design, Manufacturing \& Engineering Management, University of Strathclyde, Glasgow G1 1XJ, Scotland, UK
Department of Mechanical Engineering, Imperial College London, Exhibition Rd, London SW7 2AZ, UK

4 Department of Materials and Production Engineering, King Mongkut's University of Technology North Bangkok (KMUTNB), Bangsue, Bankok, Thailand

5 Department of Mechanical Engineering, College of Engineering, Anna University, Chennai, Tamilnadu, India 
The authors regret that in the above article, Figs.7 contained errors and were corrected as follows:
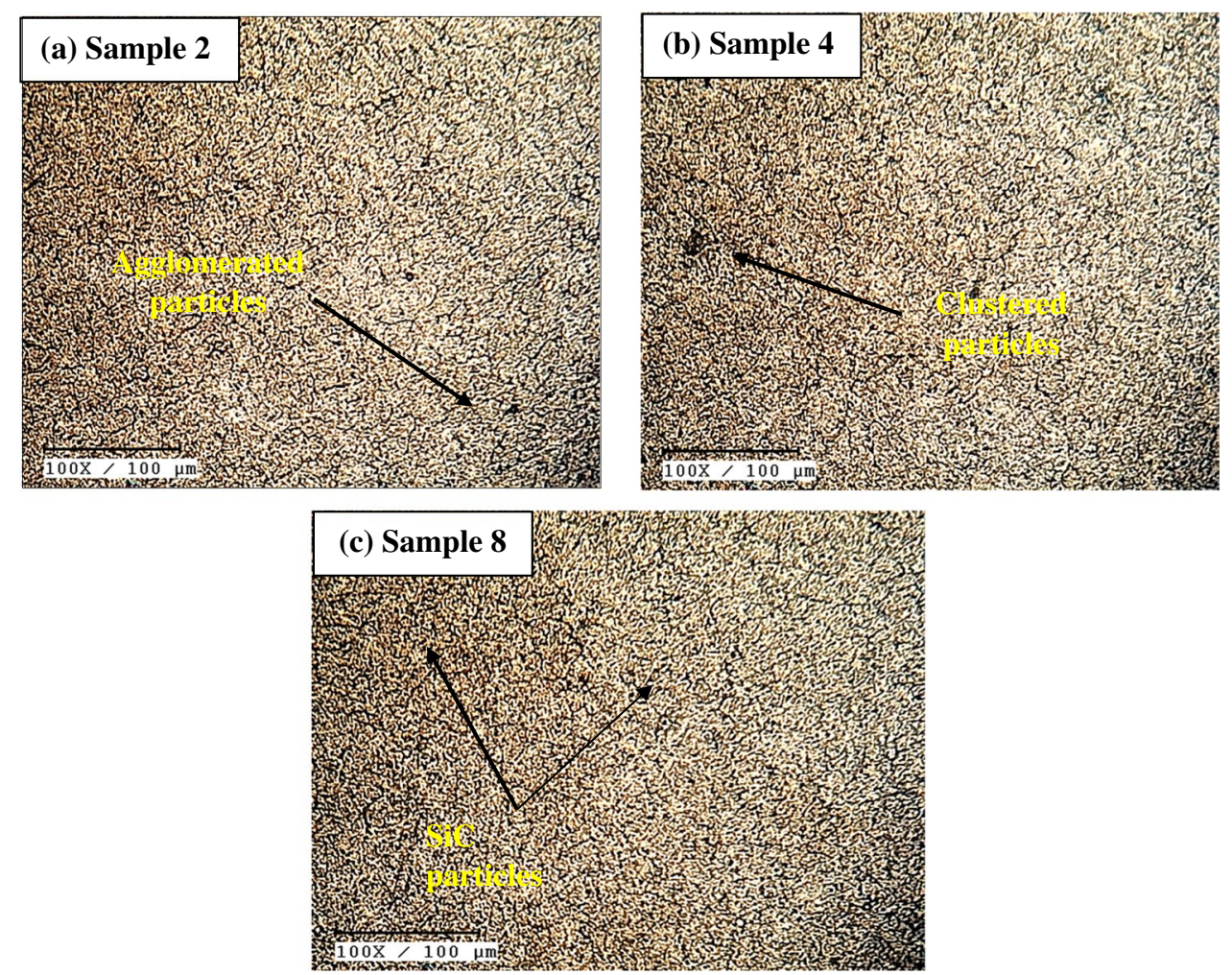
The authors regret that in the above article, Figs. 8 contained errors and were corrected as follows:
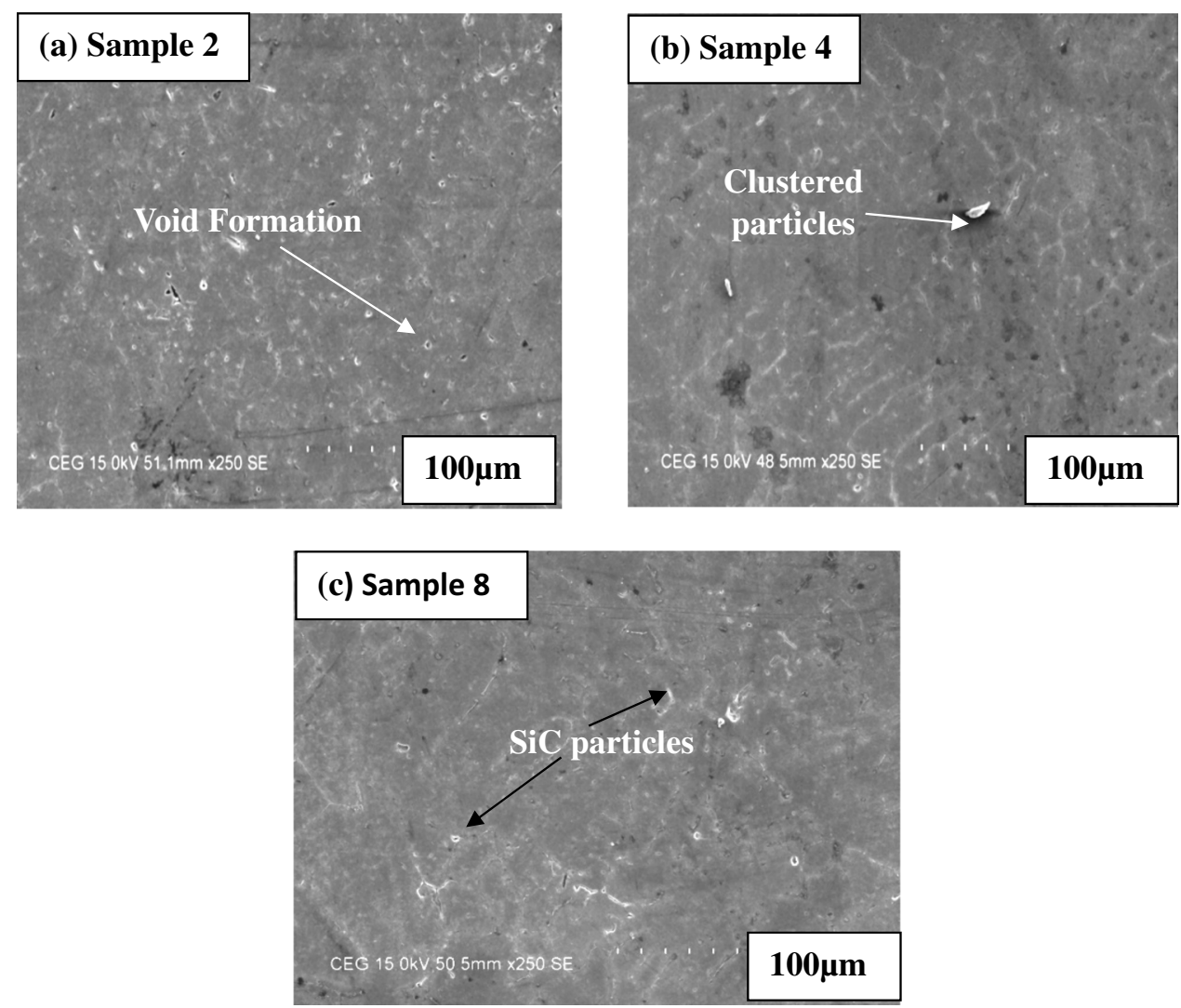

Publisher's Note Springer Nature remains neutral with regard to jurisdictional claims in published maps and institutional affiliations. 